\title{
End-of-life decision-making in respiratory intermediate care units: a European survey
}

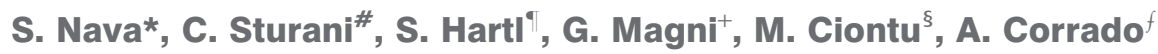 \\ and A. Simonds** on behalf of the European Respiratory Society Task Force on \\ Ethics and decision-making in end stage lung disease
}

\begin{abstract}
A survey was performed on behalf of the European Respiratory Society to assess end-of-life practices in patients admitted to European respiratory intermediate care units and high dependency units over a 6-month period.
\end{abstract}

A 33-item questionnaire was sent by e-mail to physicians throughout Europe and the response rate was $28(29.5 \%)$ out of 95 . A total of 6,008 patients were admitted and an end-of-life decision was taken in $1,292(21.5 \%)$. The mortality rate in these patients was $68 \%(884$ out of 1,292$)$.

The patients received similar proportions of withholding of treatment (298 (23\%) out of 1292), do-not-resuscitate or do-not-intubate orders $(442(34 \%)$ out of 1,292$)$ and noninvasive mechanical ventilation as the ceiling of ventilatory care $(402(31 \%)$ out of 1,292$)$. Withdrawal of therapy was employed in 149 (11\%) out of 1,292 patients and euthanasia in one. Do-not-intubate/do-notresuscitate orders were more frequently used in North compared with South Europe. All of the 473 competent patients directly participated in the decision, whereas, in 722 (56\%) out of 1,292 cases, decision-making was reported to be shared with the nurses.

In European respiratory intermediate care units and high dependency units, an end-of-life decision is taken for $\mathbf{2 1 . 5 \%}$ of patients admitted. Withholding of treatment, do-not-intubate/do-notresuscitate orders and noninvasive mechanical ventilation as the ventilatory care ceiling are the most common procedures. Competent patients are often involved, together with nurses.

KEYWORDS: Chronic obstructive pulmonary disease, end-of-life decisions, end-stage respiratory diseases, ethics, noninvasive mechanical ventilation respiratory intermediate care unit, survey

$\mathrm{n}$ most Western countries, $\sim 1 \%$ of the population dies annually. Although advances in medicine have greatly improved the ability to treat seriously ill patients and prolong life, there is increasing recognition that extension of life might not always be an appropriate goal.

The 5th International Consensus Conference in Critical Care on challenges in end-of-life care in the intensive care unit (ICU) [1] identified numerous problems, including: 1) variability in practice; 2) inadequate predictive models for death; 3) poor knowledge of patient preferences; 4) poor communication between staff and patients/ surrogate decision-makers; 5) insufficient training of healthcare providers; 6) the use of imprecise and insensitive terminology; and 7) incomplete documentation within the medical records. It was, therefore, recommended that research should be conducted to improve endof-life care.
Chronic obstructive pulmonary disease (COPD), lung cancer, upper and lower respiratory tract infections and restrictive thoracic disorders, including neuromuscular diseases, are the leading causes of death, in that they jointly account for $\sim 30 \%$ of deaths [2]; moreover, their prevalence is very likely to increase into the 2020s [3].

Acute-on-chronic respiratory failure is usually the final pathway of these pathologies. A European Respiratory Society (ERS) survey on the epidemiology of respiratory intermediate care units (RICUs) in Europe [4] has clearly shown that the large majority of patients with end-stage chronic respiratory disorders are treated by pulmonologists in those specialised areas. RICUs differ substantially from classical ICUs in terms of patient population, staffing, monitoring systems and, last but not least, use of noninvasive mechanical ventilation (NIMV) as the preferred ventilatory approach where applicable.

\section{AFFILIATIONS}

*Respiratory Intensive Care Unit, S. Maugeri Foundation, Scientific Institute of Pavia, Pavia,

${ }^{\#}$ Respiratory Intensive Care Unit, Poma Hospital, Mantua, ${ }^{+}$Statistician QBGROUP, Padua, and ${ }^{f}$ Respiratory Intensive Care Unit, Careggi Hospital, Florence, Italy. "Respiratory Intensive Care Unit, Social Medical Centre, Vienna, Austria.

${ }^{\S}$ Respiratory Intensive Care Unit, Marius Nasta National Institute of Pneumology, Bucharest, Romania. **Academic Dept of Sleep and Breathing, Royal Brompton Hospital, London, UK.

CORRESPONDENCE

S. Nava

Respiratory Intensive Care Unit

Fondazione S.Maugeri

I.R.C.C.S.

Istituto Scientifico di Pavia

Via Maugeri 10

27100 Pavia

Italy

Fax: 39382592075

E-mail: snava@fsm.it

Received:

October 022006

Accepted after revision:

February 142007

STATEMENT OF INTEREST

None declared.

European Respiratory Journal

Print ISSN 0903-1936

Online ISSN 1399-3003 
In chronically ill respiratory patients, for example, the decision to institute or withdraw acute or chronic mechanical ventilation usually requires the active participation of the patient [5-7]. Physicians and educators should target the patient and their caregivers in advance in order to improve education regarding diagnosis and probable disease progress, treatment, prognosis, palliative care options and advance care planning, especially for those who have had a previous episode of hypercapnic respiratory failure requiring NIMV or who are at high risk of ventilatory decompensation.

Unfortunately, all of the largest studies [8, 9], consensus conferences [1], and reviews regarding end-of-life decisions have been performed with reference to acute patients admitted to the ICU, and, therefore, may not necessarily apply to chronic respiratory patients and pulmonary physicians or associated personnel.

The ERS Respiratory Intensive Care Assembly has formed a task force on "ethics and decision-making in end stage lung disease", with the purpose of evaluating the current epidemiology, practice, behaviours and attitudes towards end-of-life decision-making in respiratory units that treat or monitor patients with end-stage respiratory failure in Europe.

\section{METHODS}

The aim of this task force, conducted between May 1, 2005 and October 31, 2005, was to collect data regarding end-of-life decisions in RICUs and high dependency units (HDUs) within Europe by means of a prospective questionnaire. This questionnaire was developed by the two chairmen of the task force (S. Nava and A. Simonds), further developed at the ERS annual congress in September 2004, with the help of task force members, and thereafter sent to the ERS office for formal evaluation by two external reviewers.

Once approved by the ERS office, a formal letter was sent by e-mail to all of the participants in the census on the epidemiology of RICUs in Europe, performed in 2002, and all members of the ERS Respiratory Intensive Care Assembly to invite them to participate in the present study.

Task force members from Italy, UK, Germany, Austria, France, Turkey and Romania were contacted as key informants for their own country in order to identify newly opened units or incomplete recruitment. Three reminder e-mails of invitation were sent over 4 weeks to the potential participants, after which recruitment of units was considered closed.

The questionnaire was developed specifically for the task force (by QBGROUP, Padua, Italy) and was sent by e-mail to each physician who agreed to take part in the study, as well as being available on a dedicated Website for the duration of the study. The questionnaire is shown in the Appendix and includes: 15 questions concerning the nature and epidemiology of end-oflife decisions taken in each unit during the 6-month period; nine questions about communication of these decisions; and nine general questions about the unit's organisation, the types of patient usually admitted, and the responder's characteristics. The responders who agreed to participate received a Microsoft Excel file to help them record data in real time and avoid missing information when entering the data on the Website.
After completion of the 6-month data collection, 1 month was allowed for questionnaire completion and data assimilation. Any point of ambiguity was clarified by e-mail and telephone survey. In order to enter the requested data anonymously, each participating centre was able to access the Website questionnaire by means of specific passwords.

At the end of the 6-month period, three e-mails of reminder were sent to those who had agreed to participate, after which time the website was closed. A code generated by computer program was assigned to each unit so that all data were treated anonymously, although they were identifiable by country of origin.

Table 1 reports the mutually exclusive criteria (except for the principle of double effect) adopted in order to define the concepts of end-stage respiratory care and all the end-of-life decisions included in the questionnaire. Do-not-intubate (DNI) and do-not-resuscitate (DNR) orders were placed together. As it has previously been shown that significant differences in end-of-life care occur in Europe depending on geographical location [8], an arbitrary division was applied a priori to the data analysis between North Europe (Germany, UK, Austria, France, Belgium and France; in France, the two centres were located in the northern region) and South Europe (Italy, Spain, Portugal, Turkey and Romania).

The data are presented as a whole and stratified according to geographical area (North and South Europe). All of the variables collected were analysed and tested, where appropriate, to verify the differences in distribution between the two groups (North/South Europe), using univariate analysis. In particular, the Chi-squared test was used to assess the distribution of qualitative variables by area (i.e. religion of participating physicians and types of RICU), whereas an unpaired t-test was used for the analysis of differences in the means of quantitative variables (i.e. percentage of patients receiving withholding, withdrawing or DNI/DNR order or in whom NIMV was the ceiling of ventilatory care and the number of persons involved in the decisions). These variables were considered quantitative since information was obtained at the centre level and not by single patient.

The reasons for withholding or withdrawing decisions were assessed using a rating system of $1-10$, where 1 was the most important reason and 10 the least important.

Multivariable ANOVA was performed, inserting one quantitative variable at a time, as dependent variables, versus two independent variables (geographical location and number of cases). This was done in order to verify the impact of the different number of patients enrolled by centre and the geographical location (North versus South Europe) of the unit on the variables analysed.

\section{RESULTS}

In total, 141 e-mails were sent to potential participants in the study. Of the responders, 24 stated that another physician from their RICU had already agreed to participate, nine answered that their unit had been closed or transferred, eight declined to participate and 36 never replied; 13 e-mails were returned because they were wrongly addressed. Therefore, 55 out of 95 agreed to participate; the 46 duplicates or wrongly addressed 


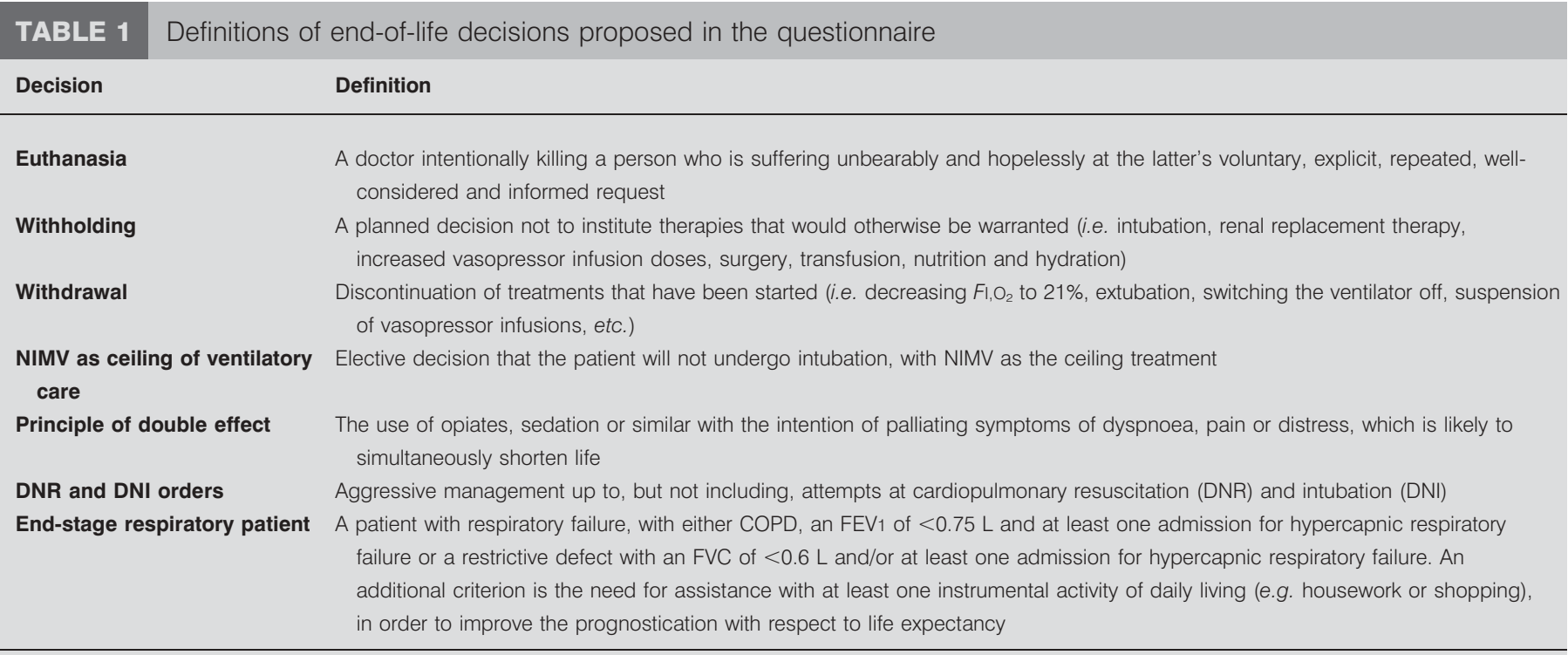

NIMV: noninvasive mechanical ventilation; DNR: do not resuscitate; DNI: do not intubate; $\mathrm{Fl}, \mathrm{O}_{2}$ : inspiratory oxygen fraction; COPD: chronic obstructive pulmonary disease; FEV1: forced expiratory volume in one second; FVC: forced vital capacity.

e-mails and units that had shut were excluded. Ultimately, 28 $(29.5 \%)$ out of 95 questionnaires were returned, despite reminder e-mails. Multiple responses from the same institution were eliminated. The geographical distribution of the institutions was as follows: Italy $(11 ; 37.9 \%)$, Germany $(6 ; 20.6 \%)$, Turkey $(2 ; 6.8 \%)$, the UK $(2 ; 6.8 \%)$, France $(2 ; 6.8 \%)$, Spain (1; 3.4\%), Austria (1; 3.4\%), Romania (1; 3.4\%), Belgium $(1 ; 3.4 \%)$, and Portugal $(1 ; 3.4 \%)$.

\section{End-of-life decisions}

A total of 6,008 patients were admitted to the 28 RICUs/HDUs during the 6-month study period; 153 patients were refused RICU admission, mainly because of a lack of beds. An end-oflife decision was taken by the attending physicians in 1,292 $(21.5 \%)$ patients, and this rate was equally distributed between units in North and South Europe (802 (23.2\%) out of 3,462 and $490(19.2 \%)$ out of 2,546 , respectively). The mortality rate in these patients was $884(68.4 \%)$ out of 1,292. Of these, 149 $(11.5 \%)$ out of 1,292 were affected by neuromuscular pathologies (i.e. spinal muscular atrophy type II $(n=16)$, spinal muscular atrophy type I $(n=6)$, amyotrophic lateral sclerosis $(n=71)$ and Duchenne muscular dystrophy $(n=56))$, whereas all of the others had COPD or restrictive disorders not related to a neuromuscular pathology. Figure 1 shows the overall percentage of end-of-life decisions taken for the 1,292 patients and their geographical division (North Europe versus South Europe). Overall, the patients received a similar rate of withholding of treatment, DNR/DNI orders or NIMV as the ceiling of ventilatory care. In the latter group, 158 (39.3\%) out of 402 patients received NIMV solely as a palliative care strategy, mainly to reduce dyspnoea. One case of euthanasia was reported. A DNR/DNI order was used in a significantly higher proportion of patients in North Europe (41.0 versus $23.2 \%$; $=0.03$ ), whereas withholding of treatment was employed more in South Europe, even though this did not reach significance (13.1 versus $30.2 \% ; p=0.077$ ). The use of
NIMV and withdrawing of treatment were similar in the two geographical areas.

The reasons for withholding and withdrawing therapy are described in tables 2 and 3. Prediction of a low probability of hospital survival or poor functional status following hospital discharge, as estimated by the attending physician, were the main reasons for withholding therapy. A direct decision made by the patient was considered of greater importance in only two cases. Concerning the withdrawal decision, the large majority of responders rated the prediction of a low probability of hospital survival as the most important determinant, followed by their perception of the patient's preference and a

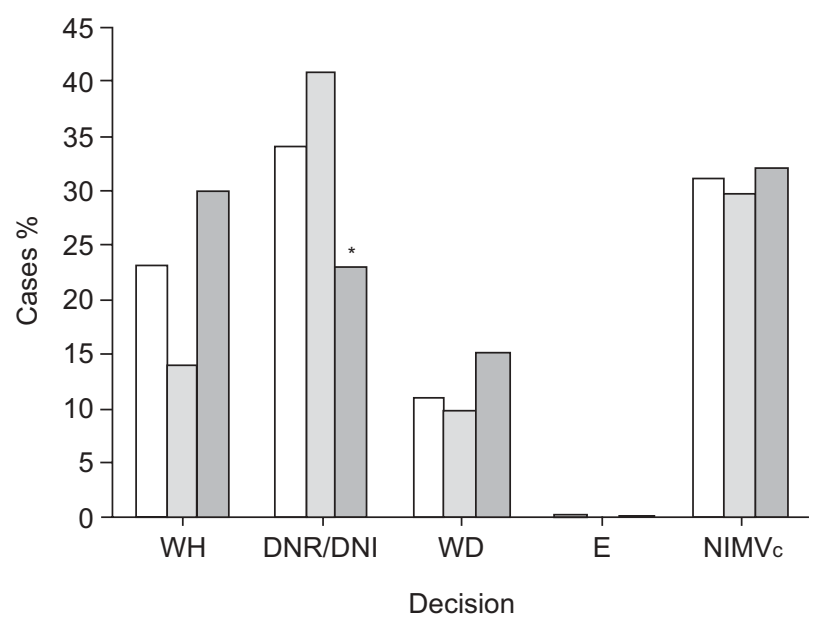

FIGURE 1. Frequency of different end-of life decisions among the patients by geographical area ( $\square$ : total $(n=1,292) ; \quad \square$ : North Europe; $\square$ : South Europe). WH: withholding of treatment; DNR: do-not-resuscitate order; DNI: do-not-intubate order; WD: withdrawal of therapy; E: euthanasia; NIMVc: noninvasive mechanical ventilation as ceiling of ventilatory care. *: $p<0.05$. 
TABLE 2 Reason for withholding decision ranked by importance

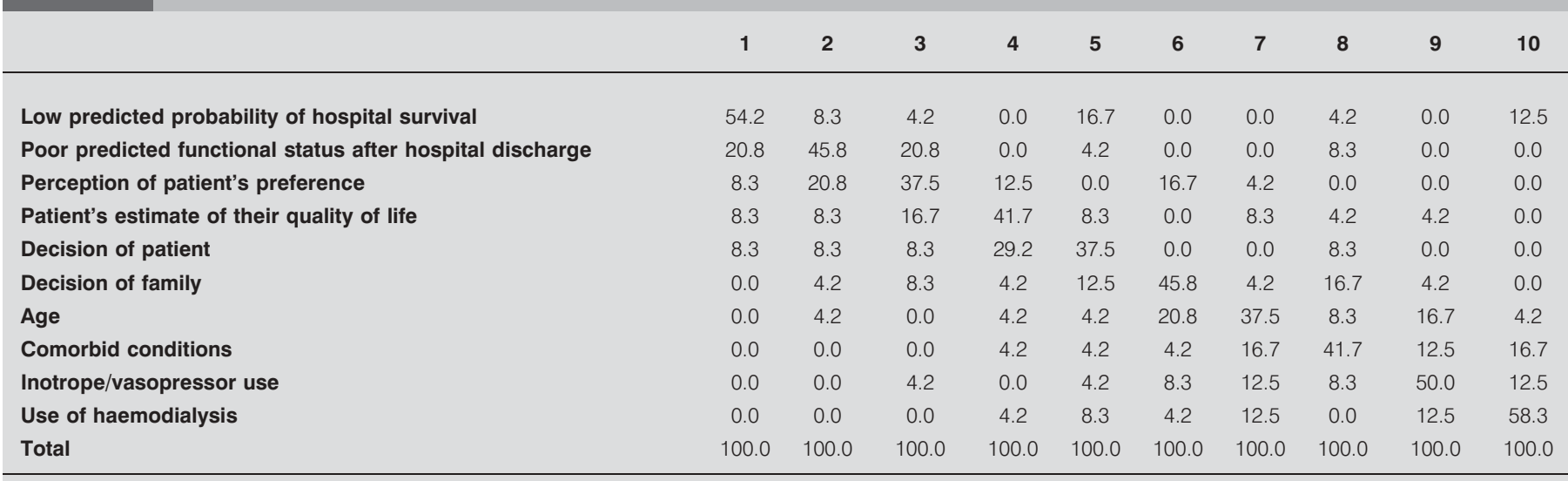

Data are presented as percentages. $1=$ most important reason; $10=$ least important reason. $n=24$ responders

direct decision by the patient. Age was also considered an important factor. No significant difference was observed when the responses were divided according to geographical area.

The principle of double effect, not mutually exclusive with other end-of-life decisions, was applied in $250(16.9 \%)$ patients (17.4\% in North Europe and $16.2 \%$ in South Europe).

The end-of-life decisions were not significantly influenced by the size of the individual centre, as evaluated by multivariate ANOVA.

\section{Communication and making the end-of-life decision}

In Europe, the use of advance directives is relatively rare, as $29.5 \%$ of the patients admitted to the RICUs/HDUs had had a formal discussion about end-of-life decisions and/or signed a living will before hospital admission. Figure 2 shows the overall percentage of patients, family or hospital personnel (not mutually exclusive) involved in the end-of-life decisions in the 1,292 patients and their geographical division (North versus South Europe). All patients considered competent (473 out of 1,$292 ; 36.6 \%$ ) were directly involved in the decision.
Interestingly, in $57.2 \%$ of cases, the patient's family was also involved, together with the patient or alone; however, this approach was more pronounced, although not significantly, in South Europe. Nurses were reported as part of a shared decision in $55.9 \%$ of cases, but this approach was more popular in North Europe. In a small minority of cases, help was sought from an Ethics Committee, other physicians (not attending), a psychologist and/or psychiatrist, a respiratory therapist or a religious advisory. Religious advice or support from a priest, imam, clergyman or similar was directly requested by the patients or their relatives in $28.9 \%$ of cases. Interestingly, in 10 RICUs (five in Italy, two in Turkey, and one in each of Spain, Romania and Belgium), it was reported that none of the patients sought religious help, whereas in a UK and an Italian RICU the percentages were 89 and $57 \%$, respectively.

Formal discussion with patients and relatives about end-of-life decisions was reported to be a routine practice in eight of the $28(28.5 \%)$ RICUs, a sporadic practice in $18(64.2 \%)$ and never performed in two $(7.1 \%)$, with a homogeneous geographical distribution.

TABLE 3 Reason for withdrawing decision ranked by importance

\begin{tabular}{|c|c|c|c|c|c|c|c|c|c|}
\hline Low predicted probability of hospital survival & 65 & 5 & 0 & 30 & 0 & 0 & 0 & 0 & 0 \\
\hline Perception of patient's preference & 15 & 10 & 45 & 5 & 15 & 5 & 5 & 0 & 0 \\
\hline Decision of patient & 15 & 15 & 0 & 50 & 5 & 5 & 5 & 5 & 0 \\
\hline Decision of family & 0 & 10 & 15 & 0 & 45 & 0 & 25 & 5 & 0 \\
\hline Inotrope/vasopressor use & 0 & 0 & 0 & 0 & 10 & 15 & 0 & 60 & 15 \\
\hline Use of haemodialysis & 0 & 0 & 0 & 5 & 0 & 15 & 0 & 5 & 75 \\
\hline Total & 100 & 100 & 100 & 100 & 100 & 100 & 100 & 100 & 100 \\
\hline
\end{tabular}

Data are presented as percentages. $1=$ most important reason; $9=$ least important reason. $\mathrm{n}=20$ responders. 


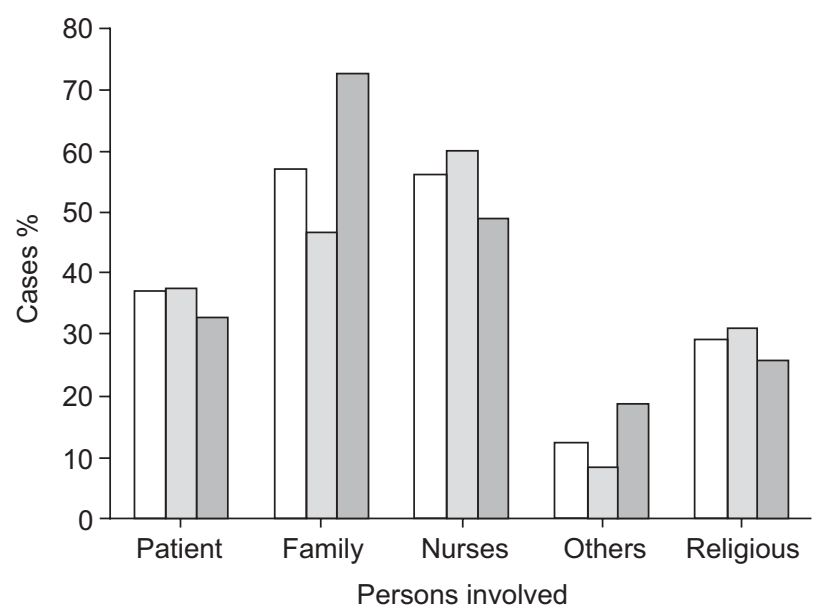

FIGURE 2. Frequency of involvement of patients, family and hospital personnel in end-of-life decision-making by geographical area ( $\square$ : total

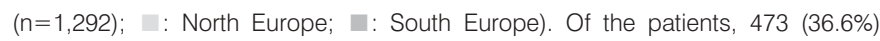
were considered competent by the attending physicians.

\section{Characteristics of RICUs/HDUs and responders}

Most (46.4\%) of the RICUs / HDUs were in university hospitals, followed by university-affiliated hospitals (21.4\%), community hospitals $(14.3 \%)$, rehabilitation or weaning centres $(7.1 \%)$, and other types of hospital $(10.7 \%)$. The number of beds were $<5$ in $17.8 \%$ of units, $5-10$ in $32.1 \%, 10-15$ in $28.5 \%$ and $>15$ in $21.4 \%$.

As shown in table 4, the mean age of the responders was $\sim 45$ yrs, with different religions and relatively high specialty interest in end-of-life care. In particular, 17 responders were aware of and considered in their decisions, national or international guidelines or consensus conference reports. Very few responders had attended more than two meetings on this topic during the study period.

\section{DISCUSSION}

The main finding of the present multicentre study is that $21.5 \%$ of patients admitted with respiratory failure to European RICUs or HDUs had an end-of-life decision taken during their hospital stay. The most common practices were withholding treatment, use of NIMV as the therapy ceiling and provision of a DNR/ DNI order, this latter practice being employed significantly more frequently in North Europe than in South Europe.

Improvement in the standards of end-of-life care and decisionmaking has been increasingly recognised as a high priority in present-day society. Interest in the topic is generally high, in part due to increasing attention from the media, particularly in some high-profile cases [10-12], which have generated debate between physicians, lawyers, ethicists, religious groups, patients' associations and the population as a whole.

The vast majority of the studies assessing the practice of endof-life care have been performed in general ICUs [8, 9], and so limited data are available regarding the approaches of medical teams in other more specific environments and other subsets of patients.

For example, chronic diseases are the leading cause of death; the World Health Report of 2003 stated that the burden of these

\begin{tabular}{lc} 
TABLE 4 & $\begin{array}{c}\text { Characteristics of the physicians who responded } \\
\text { to the questionnaire }\end{array}$ \\
Subjects & 28 \\
Age yrs & $45.1 \pm 7.4$ \\
Religion & \\
Catholic & 12 \\
Protestant & 5 \\
Muslim & 2 \\
Jewish & 2 \\
Orthodox & 1 \\
None & 6 \\
Sex M/F & $23 / 5$ \\
End-of-life articles read in last $\mathbf{6}$ months & 2 \\
0 & 18 \\
1-5 & 4 \\
$6-10$ & 4 \\
>10 & \\
End-of-life symposia attended in last $\mathbf{6}$ months & \\
0 & \\
1 & 8 \\
2 & 10 \\
3 & 8 \\
Use of national or international guidelines in & 1 \\
end-of-life decision Y/N & \\
\hline
\end{tabular}

Data are presented as $n$ or mean \pm SD. M: male: F: female; Y: yes; N: no. *: only 27 physicians responded to this question.

diseases will increase dramatically during the next 15 yrs [3] Chronic respiratory disorders are now considered to be one of the five leading causes of death in both Western and developing countries. It is, therefore, not surprising that the large surveys of end-of-life care performed in ICUs report respiratory disorders as the major cause of admission [8, 9].

The final common pathway of patients with chronic respiratory disorders is very often the occurrence of chronic and/or acute respiratory failure. These patients are often followed periodically as outpatients or inpatients by respiratory specialists, who usually direct therapeutic interventions, such as long-term oxygen therapy or long-term mechanical ventilation. The relatively recent growth in the number of RICUs / HDUs in Europe [4] has provided a unique opportunity to assess the approach of respiratory medical and paramedical specialists towards end-of-life care and decisions in this particular population of patients. Despite the fact that the present questionnaire was sent out to the ERS mailing list for RICUs, the geographical distribution of responders is clearly unbalanced, with Italy and Germany accounting for $>60 \%$ of the RICUs. Interestingly, this distribution is almost identical to that identified by the ERS survey on European RICUs [4], and is, therefore, in keeping with the high prevalence of units in some countries and lack of such facilities in others.

\section{Types and frequencies of end-of-life decision}

The present survey demonstrates that, among European RICUs/HDUs, $21.5 \%$ of patients admitted had limitations imposed on life-sustaining therapy. This percentage is higher 
than that observed in other studies performed in ICUs in different European $[8,13,14]$ and North American countries [9, $15,16]$. Comparison with these ICU-based studies is difficult; however, previous investigations have also shown greater limitation of life-sustaining therapy in elderly patients [13] and for certain diagnostic categories, such as respiratory failure [14], and so it is not surprising that elderly patients affected by chronic respiratory disorders did not receive unlimited support during the RICU admission.

Withholding of treatment, use of NIMV as the treatment ceiling and DNR orders accounted for $>80 \%$ of end-of-life decisions. Withdrawing was rarely used in European RICUs, mainly because NIMV was used as the ceiling of ventilatory care in almost a third of the patients. Indeed, NIMV has been used increasingly as an alternative to invasive ventilation in patients with a DNI order $[17,18]$. In a recent study [17], NIMV was applied to treat episodes of acute respiratory failure in 114 patients with DNI orders. Approximately half of the patients survived and were discharged from the ICU. Similar results have recently been obtained by SCHETTINO et al. [18], and so there is increasing recognition that NIMV may be an effective alternative to intubation, especially in those patients in whom an invasive approach is questioned because of the presence of chronic disease or poor life expectancy. Interestingly, in $40 \%$ of patients undergoing NIMV, this was used solely as a palliative treatment, as it has been shown in a pilot study that dyspnoea can be improved in a subset of patients requiring only palliative treatment [19]. However, further studies are needed in order to determine the appropriate use of NIMV in this instance. It is also possible that NIMV was used as the treatment ceiling, especially in those patients already receiving chronic noninvasive ventilation, but no data concerning this issue were available from the survey.

Internationally recognised definitions have been used in the present survey. However, overlap between some categories may have occurred. For example, the use of NIMV as the treatment ceiling may be considered to equate to a DNR/DNI order, and can also be considered a form of withholding.

The indications given for withdrawing and withholding treatment were very similar and related to the judgement of the physician involved in the decision. This is much in keeping with the results of a multinational study [20], in which the strongest determinants of withdrawal were the physician's perception that the patient preferred not to use life support and the physician's predictions of a low likelihood of survival and of poor cognitive function. Unfortunately, as documented by the low percentage of patients admitted to RICUs/HDUs with written or verbal advance directives, it is difficult to know whether the physician fully understood the wishes of the patients who did not have the capacity for decision-making.

The DNR/DNI order was a frequently used end-of-life decision in European RICUs/HDUs. The reasons underlying this decision were not specifically assessed in the questionnaire, but, again, it seems likely that these may be related to the physician's estimate of poor prognosis of the patient. This was also the only practice that significantly differed between the northern and southern regions of Europe. This confirms a very recent study showing that the DNR order is a common phenomenon in North European countries and Switzerland, but not in Italy [21]. Religious affiliations have been suggested to influence physician attitudes towards ethical decisions [8], but this was not the case in the present study, although a detailed analysis was not possible due to the small number of responders.

Interestingly, FERRAND et al. [14] have shown that withholding therapy was associated with a mortality of only $56 \%$, compared with a mortality of $>90 \%$ after withdrawal decisions. Since very few patients in the present study underwent withdrawal of therapy, it is not surprising that the overall mortality rate in the present sample was below the percentage usually reported in ICU studies. Additionally, the way in which end-of-life decisions were handled is likely to be influenced by other factors, such as the age, skill and experience of the attending physicians. Last but not least, the existing local legislation and guidelines concerning the end-of-life decision may vary dramatically among the different European countries. For example, in the Netherlands, withholding, withdrawal and euthanasia are legally covered in the law on contracts for medical treatment [22]; in Belgium, despite there being no law covering end-of-life care in the ICU, it is no longer a criminal offence to commit euthanasia if several strict conditions are fulfilled [23]. Conversely, in Italy, the legal context of end-oflife decision is very confused because of the lack of specific laws, and the decision must be made on the basis of civil and penal codes of law that date from the 1940s [24].

\section{Communication and making the end-of-life decision}

As shown in several previous studies [8, 9, 13-16], only a relatively small percentage $(<40 \%)$ of the patients participated in decision-making. It is advocated that end-of-life decisions should be discussed directly with the patient, if competent, and with the family [1]. Several studies [25, 26] have shown that inadequate and insufficient communication between medical staff and members of the family is a key issue. For example, it has been reported [25] that, in some countries, e.g. Sweden and Italy, in $>50 \%$ of patients (competent and incompetent) undergoing end of life decisions, these were discussed with neither the patient nor with relatives. Indeed, families consistently rate communication with hospital staff as their most important concern [26].

In the present survey, competent patients were directly involved in the decisions, and, in more than half of cases, the family was also contacted. The family was much more involved in decision-making in South Europe. Nurses were involved in the decisions in a proportion that was very similar to that described by FERRAND et al. [27], and was relatively constant among the different RICUs/HDUs, although it has previously been shown that the participation of the nursing staff in ethical decisions varies considerably. Most of the decisions were taken by the single attending physician/team, since other senior colleagues were rarely involved in the decisions and advice was infrequently sought from other professionals, such as psychologists or members of the ethical committee and spiritual advisors.

This is the first report aiming to assess the participation of a patient's or relatives' requests for a religious figure, such as a priest, imam or rabbi. In $\sim 30 \%$ of cases, the hospital personnel 
were asked to call one of these spiritual advisers, and, contrary to expectations, this approach was more popular in North versus South Europe. This may partly reflect the fact that, in some units, religious advisors visit routinely and are, therefore, more accessible to patients and families.

\section{CONCLUSIONS}

Despite the relatively low rate of response to the present survey, this study showed that, in European respiratory intermediate care units and high dependency units, an endof-life decision is taken for $\sim 30 \%$ of the patients admitted. The most common practices were withholding treatment, the use of noninvasive mechanical ventilation as a ceiling therapy and provision of a do-not-resuscitate/do-not-intubate order, the latter occurring significantly more frequently in North Europe compared with South Europe. Patients, when competent, and their families are often involved, together with nurses, in reaching these key decisions.

\section{ACKNOWLEDGEMENTS}

The authors would like to thank the European Respiratory Society Task Force advisory team members: M. Elliott (Respiratory Unit, St James's University Hospital, Leeds, UK), B. Schonhofer (Respiratory Unit, Oststadt Hospital, Hanover, Germany), N. Ambrosino (Respiratory Unit, Cisanello Hospital, Pisa, Italy) and G. Baum (USA/Israel). The authors would also like to acknowledge the study participants who responded to the questionnaire: D. Rodenstein (Brussels, Belgium); A. Demoule (Paris, France); A. Cuevelier (Rouen, France); T. Barchfeld (Schmallenberg-Grafschaft, Germany); O. Karg (Gauting, Germany); B. Schonhofer (Hanover, Germany); T. Welte (Hanover, Germany); G. Nilius (Hagen, Germany); M. Westhoff (Hemer, Germany); M. Confalonieri (Trieste, Italy); C. Sturani (Mantua, Italy); A. Potena (Ferrara, Italy); A. Corrado (Florence, Italy); M. Moretti (Modena, Italy); N. Ambrosino (Pisa, Italy); E. Clini (Pavullo, Italy); P. Ceriana (Pavia, Italy); M. Vitacca (Gussago, Italy); A. Vianello (Padua, Italy); R. Scala (Arezzo, Italy); S. Hartl (Vienna, Austria); J.C. Winck (Vila Nova de Gaia, Portugal); M. Ciountu (Bucharest, Romania); J.L. Lopez-Campos (Cadiz, Spain); Ç. Turgay (Istanbul, Turkey); O. Dikensoy (Gaziantep, Turkey); S.W. Banham (Glasgow, UK); and A.K. Simonds (London, UK).

\section{APPENDIX}

\section{SECTION 1}

1) How many patients did you admit to your Unit during the study period?

2) How many patients died in your Unit during the study period?

3) How many patients were discharged from your Unit in a terminal phase of their disease, after withdrawing and/or withholding any therapy?

4) How often did you give a "do not resuscitate" or "do not intubate" order in the group of patients admitted to your Unit? 5) How often did you practice withholding of therapy (eg. inotropic support, renal replacement therapy, invasive mechanical ventilation) in the group of patients admitted to your Unit?
6) Give the reasons more likely to influence your withholding decision, by ranking 1-10 in order of importance (most important first):
I_l_l Prediction of low probability of hospital survival
I_l_ I Prediction of poor functional status after hospital discharge
I_ I_I Perception of patient's preference
I_ I_l Patient's estimate of his/her quality of life
I___ I Decision of the patient
I___ I Decision of the family
I_I_l Age
I_l_l Presence of co-morbidities
I_l_ I Use of inotropes or vasopressor
I_ I_I Use of haemodialysis

7) How often did you practice withdrawing treatment in the group of patients admitted to your Unit?

8) Give the reasons more likely to influence your withdrawing decision, by ranking 1-9 in order of importance (most important first):

I__ I Prediction of poor likelihood of hospital survival

I__ Prediction of poor functional status after hospital

I_I Perception of patient's preference (verbal or advance directive)

I_ I Decision of the patient

I_I Decision of the family

I_I Age

I__ I Presence of co-morbidities

I__ I Use of inotropes or vasopressor

I__ I Use of haemodialysis

9) How many patients receive NIV as the ceiling of ventilatory care (i.e. elective decision they will not receive invasive ventilation) if deterioration occurs?

10) How many patients received NIV solely as a palliative care strategy e.g. to reduce dyspnoea?

11) How many times did you refuse RICU/HDU admission in a patient with end-stage respiratory disorder and a poor life expectancy?

12) How often did you use the "principle of double effect" in patients admitted to your Unit?

(i.e. use of opiates or sedatives to reduce symptoms of dyspnoea, pain or distress in the knowledge this same treatment may also shorten life)

13) How often did you practice euthanasia in patients admitted to your Unit?

14) How many patients who received an end-of-life decision died in your Unit during the study period?

15) How many patients who received an end-of-life decision were affected by:

Spinal muscular atrophy Type II

$\square$ Spinal muscular atrophy Type I

$\square$ Motor neurone disease (ALS)

$\square$ Duchenne muscular dystrophy

\section{SECTION 2}

16) How many of your patients who received an end-of-life decision were able to take an autonomous decision?

17) How often did you ask those patients about the "end-oflife" care?

18) How often did you ask the patient's family about the "end of life" care?

19) How often did you seek "external" help in end-of-life decision? 
20) If you were seeking external help, please specify

$\square$ Ethical Committee

Other physician

Psychologist/psychiatrist

Clergyman, priest, imam or similar

Nurses

Respiratory therapist/physiotherapist

Other: please specify:

21) How often did you involve the nurses in the end-of-life decisions?

22) How many times did you have a formal discussion with the patient and relatives at the time of admission to the Unit (or soon after) regarding end-of-life decisions?

23) How many patients and/or relatives did seek religious advice and support?

24) How many patients did employ written Advance Directives?

\section{SECTION 3}

25) Where are you from?

26) Where is your RICU located?

$\square$ University hospital

University-affiliated hospital

Community hospital

Rehabilitation centre

Other - please specify:

27) How many beds has your Unit?

28) What is your religion?

$\square$ None

Catholic

Muslim

Jewish

Protestant

Other - please specify:

29) How old are you? I_ I_ I years

30) Gender: $\square \mathrm{M} \square \mathrm{F}$

31) How many scientific articles about end-of-life decision did you read in the study period?

32) How many symposia about end-of-life decision did you attend in the study period in the major national and international meetings?

33) Please list any national or international guidelines you observe on end of life care and withholding/withdrawing therapy.

\section{REFERENCES}

1 Carlet J, Thijs LG, Antonelli M, et al. Challenges in end-of-life care in the ICU. Intensive Care Med 2004; 30: 770-784.

2 Lopez AD, Mathers CD, Ezzati M, Jamison DT, Murray CJ. Global and regional burden and risk factors, 2001: systematic analysis of population health data. Lancet 2006; 367: 1747-1757.

3 Yach D, Hawkes C, Gould CL, Hofman KJ. The global burden of chronic diseases. Overcoming impediments to prevention and control. JAMA 2004; 291: 2616-2622.

4 European Respiratory Society Task Force on epidemiology of respiratory intermediate care in Europe. Respiratory intermediate care units: a European survey. Eur Respir J 2002; 20: 1343-1350.
5 Dales RE, O'Connor A, Hebert P, Sullivan K, McKim D, Llewellyn-Thomas $\mathrm{H}$. Intubation and mechanical ventilation for COPD: development of an instrument to elicit patient preferences. Chest 1999; 116: 792-800.

6 Simonds AK. Ethics and decision making in end stage lung disease. Thorax 2003; 58: 272-277.

7 Lynn J, Ely EW, Zhong Z, et al. Living and dying with chronic obstructive pulmonary disease. J Am Geriatr Soc 2000; 48: Suppl. 5, S91-S100.

8 Sprung CL, Cohen SL, Sjokvist P, et al. End-of-Life practices in European intensive care units. The Ethicus Study. JAMA 2003; 290: 790-797.

9 Prendergast TJ, Claessens MT, Luce JM. A national survey of end-of-life care for critically ill patients. Am J Respir Crit Care Med 1998; 158: 1163-1167.

10 Gold JA. The Quinlan case: a review of two books. Am J Law Med 1977; 3: 89-94.

11 Quill ET. Terri Schiavo - a tragedy compounded. N Engl J Med 2005; 352: 1630-1633.

12 Quill ET, Meier DE. The big chill - inserting the DEA into end-of-life care. N Engl J Med 2006; 354: 1-3.

13 Vincent JL, Parquer JN, Preiser JP, Brimioulle S, Kahn RJ. Terminal events in the intensive care unit: review of 258 fatal cases in one year. Crit Care Med 1989; 17: 530-533.

14 Ferrand E, Robert R, Ingrand P, Lemaire F. Withholding and withdrawing of life support in intensive care units in France: a prospective survey. Lancet 2001; 357: 9-14.

15 Keenan SP, Busche KD, Chen LM, McCarthy L, Ihman KJ, Sibbald WJ. A retrospective review of a large cohort of patients undergoing the process of withholding or withdrawal of life support. Crit Care Med 1997; 25: 1324-1331.

16 Sprung CL, Eidelman LA, Pizov R. Changes in forgoing life-sustaining treatments in the United States: concern for the future. Mayo Clin Proc 1996; 71: 512-516.

17 Levy M, Tanios MA, Nelson D, et al. Outcomes of patients with do-not-intubate orders treated with noninvasive ventilation. Crit Care Med 2004; 32: 2002-2007.

18 Schettino G, Altobelli N, Kacmarek RM. Noninvasive positive pressure ventilation reverses acute respiratory failure in selected "do-not-intubate" patients. Crit Care Med 2005; 33: 1976-1982.

19 Cuomo A, Conti G, Delmastro M, et al. Noninvasive mechanical ventilation as a palliative treatment of acute respiratory failure in patients with end-stage solid cancer. Palliat Med 2004; 18: 602-610.

20 Cook D, Rocker G, Marshall J, et al. Withdrawal of mechanical ventilation in anticipation of death in the intensive care unit. N Engl J Med 2003; 349: 1123-1132.

21 Van Delden JJ, Lofmark R, Deliens MA, et al. Do-notresuscitate decisions in six European countries. Crit Care Med 2006; 34: 1686-1690.

22 Kompanje EJO. Care for the dying in intensive care in the Netherlands. Intensive Care Med 2006; 32: 2067-2069.

23 Vincent JL. End-of-life practice in Belgium and the new euthanasia law. Intensive Care Med 2006; 32: 1908-1911.

24 Zamperetti N, Proietti R. End of life in the ICU: laws, rules and practices: the situation in Italy. Intensive Care Med 2006; 32: 1620-1622.

25 van der Heide A, Deliens L, Faisst K, et al. End-of-life decision-making in six European countries: descriptive study. Lancet 2003; 362: 435-440. 
26 Abbott KH, Sago JG, Breen CM, Abernethy AP, Tulsky JA. Families looking back: one year after discussion of withdrawal or withholding of life-sustaining support. Crit Care Med 2001; 29: 197-201.
27 Ferrand E, Lemaire F, Regnier B, et al. Discrepancies between perceptions by physicians and nursing staff of intensive care unit end-of-life decisions. Am J Respir Crit Care Med 2003; 167: 1310-1315. 